\title{
How do the vitamin $C$ levels in fruit juices in the market today compare to the values in the Food Tables?
}

\author{
B. Modenese and P. Barra \\ Kingston University KT1 2EE, UK
}

Fruit juice is an important source of vitamin C contributing with an average of $26 \%$ of vitamin $\mathrm{C}$ intake in both males and females aged between 15 to 18 in the UK (and around $20 \%$ for all those older than four and younger than 50-64 years) ${ }^{(1)}$. Vitamin C acts as an efficient antioxidant against a wide range of intra- and extracellular free radicals ${ }^{(2)}$. Its perception as a healthy food (one of your 5-a-day) plus the wide range of different fruit juices currently available in the market may explain the large increase in consumption over the last decade ${ }^{(1)}$. The range of juices has changed considerably since the nutritional content of fruit juices was last updated on the Food Tables so that the values published for Vitamin $\mathrm{C}$ no longer reflect the average values found on fruit juices in the market today. Therefore, the aim of the present study was to quantify levels of vitamin $\mathrm{C}$ in different types of fruit juices and compare these values with those stated on both food labels and the Food Tables.

The non-spectrophotometric 2,6-Dichlorophenolindophenol (DCPIP) method was used. This method is based on the reduction of DCPIP with ascorbic acid in acidic solution with the end point noted when a pink colour residue. Standards of known concentrations were analysed to determine the amount of vitamin $\mathrm{C}$ oxidised by $1 \mathrm{ml}$ DCPIP that was later used to calculate the amount of vitamin $\mathrm{C}$ in the samples of juice. Fruit juice samples (orange, grapefruit, pineapple and apple) were directly titrated with DCPIP (in triplicates). Three brands (Tesco, Sainsbury's and ASDA), with additional own brands, were analysed for each flavour. Vitamin C content was then quantified and expressed in $\mathrm{mg} / 100 \mathrm{ml}$.

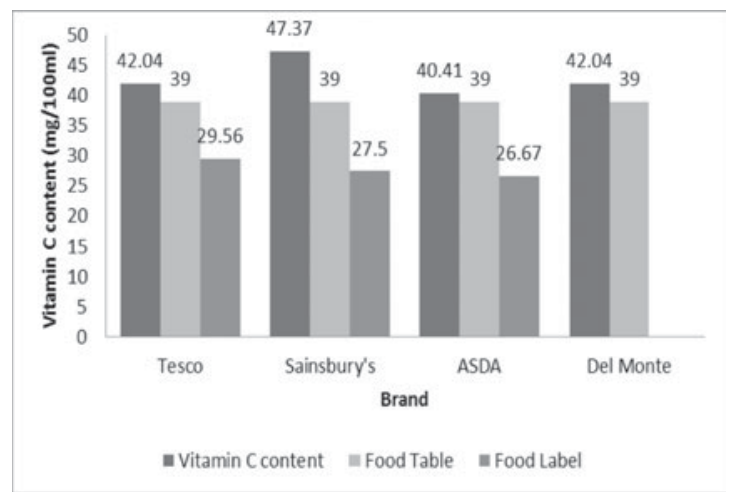

Fig. 1. Orange juice.

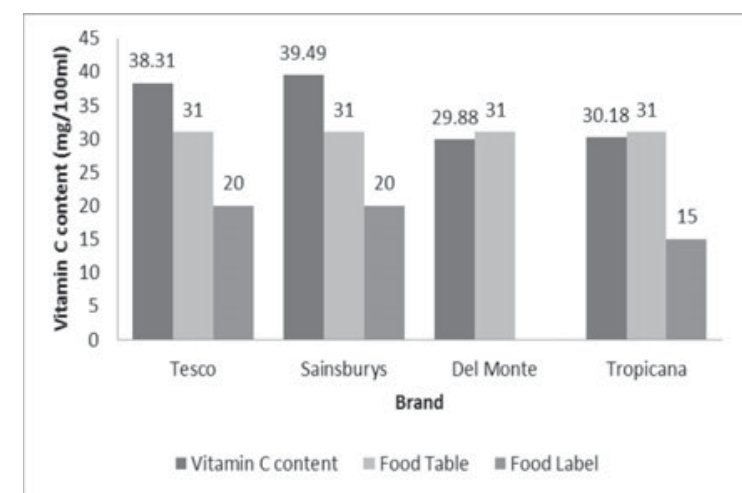

Fig. 2. Grapefruit juice

Sainsbury's branded orange juices had the highest average vitamin C content compared with Tesco, ASDA and Del Monte. In addition, orange juices had significantly more Vitamin $\mathrm{C}$ than the values stated on the food labels but similar levels, on average, to the Food Tables. Vitamin C content was very low in the majority of the apple juices with 8/13 juices having vitamin $\mathrm{C}$ contents lower than $1 \mathrm{mg} / 100 \mathrm{ml} v$. $14 \mathrm{mg} / 100 \mathrm{ml}$ in Food Tables ( $\pm 7 \%$; unpublished results). Conversely, Tesco Apple Pressed Juice contained $114 \mathrm{mg} / 100 \mathrm{ml}$ of juice (highest level of all juices). Vitamin C content in grapefruit juices was found to be $30-40 \mathrm{mg} / 100 \mathrm{ml}$ of juice across all analysed brands (Fig. 2) but also typically higher than Food Tables (25\% higher) and food labels (100\% higher). Vitamin C in pineapple juices produced mixed results - values ranged from less than $1 \mathrm{mg} / 100 \mathrm{ml}$ (in $2 / 8$ juices) to $44 \mathrm{mg}$ of vitamin $\mathrm{C} / 100 \mathrm{ml}$ of juice $(v .11 \mathrm{mg} / 100 \mathrm{ml}$ in Food Tables; unpublished results).

Consumption of fruit juices can have a significant impact on Vitamin $\mathrm{C}$ intake. Although orange juice and grapefruit juices seem to have higher values than both food labels and food tables, the vitamin $\mathrm{C}$ content of apple and pineapple juice seems to differ significantly from those published on the Food Tables (much lower). The impact of this on estimates of average population intake of Vitamin $\mathrm{C}$ has not been estimated but is unlikely to be significant (but may be significant for individuals with high intake of apple and pineapple juice). These data need to be confirmed by use of the same chromatographic methods as those used for analysis of the vitamin $\mathrm{C}$ content of fruit juices in the Food Tables.

1. Caswell H (2009) Nutr Bull 34, 273-288.

2. Benedich A, Machlin LJ, Scandurra O et al. (2007) Adv Free Rad Biol Med 2 2, 419-444. 